\title{
Efficient Recruitment of Layer 2/3 Interneurons by Layer 4 Input in Single Columns of Rat Somatosensory Cortex
}

\author{
Moritz Helmstaedter, ${ }^{1}$ Jochen F. Staiger, ${ }^{2}$ Bert Sakmann, ${ }^{1}$ and Dirk Feldmeyer ${ }^{3,4}$ \\ ${ }^{1}$ Max Planck Institute for Medical Research, D-69120 Heidelberg, Germany, ${ }^{2}$ Department of Neuroanatomy, Institute for Anatomy and Cell Biology, Albert- \\ Ludwigs-Universität, D-79104 Freiburg, Germany, and ${ }^{3}$ Research Center Jülich, Institute for Neuroscience and Biophysics, INB-3 Medicine, D-52425 Jülich, \\ Germany, and ${ }^{4}$ Department of Psychiatry and Psychotherapy, RWTH Aachen University Hospital, D-52074 Aachen, Germany
}

Interneurons in layers 2/3 are excited by pyramidal cells within the same layer (Reyes et al., 1998; Gupta et al., 2000), but little is known about translaminar innervation of these interneurons by spiny neurons in the main cortical input layer 4 (L4). Here, we investigated (1) how efficiently L4 spiny neurons excite L2/3 interneurons via monosynaptic connections, (2) whether glutamate release from axon terminals of L4 spiny neurons depends on the identity of the postsynaptic interneuron, and (3) how L4-to-L2/3 interneuron connections compare with L4-to-L2/3 pyramidal neuron connections. We recorded from pairs of L4 spiny neurons and L2/3 interneurons in acute slices of rat barrel cortex of postnatal day 20 (P20) to P29 rats. The L4-to-L2/3 interneuron connections had an average unitary EPSP of $1.2 \pm 1.1 \mathrm{mV}$. We found an average of $2.3 \pm 0.8$ contacts per connection, and the L4-to-L2/3 interneuron innervation domains were mostly column restricted. Unitary EPSP amplitudes and paired-pulse ratios in the L4-to-L2/3 interneuron connections depended on the "group" of the postsynaptic interneuron. Averaged over all L4-to-L2/3 interneuron connections, unitary EPSP amplitudes were 1.8-fold higher than in the translaminar L4-to-L2/3 pyramidal cell connections. Our results suggest that L4 spiny neurons may more efficiently recruit L2/3 interneurons than L2/3 pyramidal neurons, and that glutamate release from translaminar boutons of L4 spiny neuron axons is target cell specific.

Key words: barrel cortex; connectivity; GABAergic interneurons; layer 2/3; synaptic connection; target cell specificity

\section{Introduction}

Ensembles of neurons that represent common sensory stimuli are arranged in columns in primary sensory areas of the neocortex (Mountcastle, 1957; Hubel and Wiesel, 1969). Spiny neurons in layer 4 of a cortical column are a main target of excitatory thalamic afferents from ventroposterior medial nucleus of the thalamus (Hubel and Wiesel, 1962; Killackey, 1973; Chmielowska et al., 1989; Lu and Lin, 1993; Bruno and Sakmann, 2006). In parallel, thalamic afferents excite interneurons in layer 4, which in turn can release GABA onto spiny neurons in layer 4 (Simons, 1978; White and Rock, 1981; Agmon and Connors, 1991; Kim et al., 1995; Staiger et al., 1996; Castro-Alamancos and Connors, 1997; Gibson et al., 1999; Porter et al., 2001; Swadlow, 2002; Beierlein et al., 2003; Gabernet et al., 2005). One next stage of cortical signal flow is the excitatory projection from L4 spiny neurons to L2/3 pyramidal neurons (Armstrong-James et al., 1992; Feldmeyer et al., 2002; Shepherd and Svoboda, 2005) (for review, see Douglas and Martin, 2007; Lübke and Feldmeyer, 2007; Schubert et al., 2007). Here, we show by paired intracellular

\footnotetext{
Received Dec. 22, 2007; revised May 26, 2008; accepted June 19, 2008.

This work was supported in part by Deutsche Forschungsgemeinschaft (Sta 431/5-4). We thank Drs. Arnd Roth and Andreas Schaefer for many fruitful discussions, Dr. Andreas Schaefer for helpful comments on previous versions of this manuscript, and Marlies Kaiser and Ulrich Opfermann-Emmerich for excellent technical assistance. Correspondence should be addressed to Moritz Helmstaedter, Max Planck Institute for Medical Research, Jahnstrasse 29, D-69120 Heidelberg, Germany. E-mail: moritz.helmstaedter@mpimf-heidelberg.mpg.de. DOI:10.1523/JNEUROSCI.5701-07.2008

Copyright $\odot 2008$ Society for Neuroscience $\quad 0270-6474 / 08 / 288273-12 \$ 15.00 / 0$
}

recordings that this translaminar connection from L4 spiny neurons to excitatory L2/3 pyramidal neurons was also paralleled by a translaminar connection from L4 spiny neurons to inhibitory $\mathrm{L} 2 / 3$ interneurons. The anatomical and functional properties of these connections were characterized for the different "axonal projection types" of L2/3 interneurons and for the "groups" of L2/3 interneurons defined by dendritic, axonal, and intrinsic electrical parameters (Helmstaedter et al., 2008a,b,c).

\section{Materials and Methods}

Preparation, solutions. All experimental procedures were performed according to the animal welfare guidelines of the Max Planck Society. Wistar rats (20-29 d of age) were anesthetized with isoflurane and decapitated, and slices of somatosensory cortex were cut in cold extracellular solution using a vibrating microslicer (DTK-1000; Dosaka). Slices were cut at $350 \mu \mathrm{m}$ thickness in a thalamocortical plane (Agmon and Connors, 1991) at an angle of $50^{\circ}$ to the interhemispheric sulcus. Slices were incubated at room temperature $\left(22-24^{\circ} \mathrm{C}\right)$ in an extracellular solution containing $4 \mathrm{~mm} \mathrm{MgCl} / 1 \mathrm{mM} \mathrm{CaCl}_{2}$ to reduce synaptic activity. Slices were continuously superfused with an extracellular solution containing the following (in $\mathrm{mm}$ ): $125 \mathrm{NaCl}, 2.5 \mathrm{KCl}, 25$ glucose, 25 $\mathrm{NaHCO}_{3}, 1.25 \mathrm{NaH}_{2} \mathrm{PO}_{4}, 2 \mathrm{CaCl}_{2}$, and $1 \mathrm{MgCl}_{2}$ (bubbled with $95 \% \mathrm{O}_{2}$ and $5 \% \mathrm{CO}_{2}$ ). The pipette (intracellular) solution contained the following (in $\mathrm{mm}$ ): $105 \mathrm{~K}$-gluconate, $30 \mathrm{KCl}, 10 \mathrm{HEPES}, 10$ phosphocreatine, 4 ATP-Mg, and $0.3 \mathrm{GTP}$, adjusted to $\mathrm{pH} 7.3$ with $\mathrm{KOH}$; the osmolarity of the solution was $300 \mathrm{mOsm}$. Biocytin (Sigma-Aldrich) at a concentration of $3-6 \mathrm{mg} / \mathrm{ml}$ was added to the pipette solution, and cells were filled during $1-2 \mathrm{~h}$ of recording.

Identification of barrels and neurons. Slices were placed in the recording 
chamber and inspected with a $2.5 \times / 0.075 \mathrm{nu}-$ merical aperture (NA) Plan objective using bright-field illumination. Barrels were identified as light spots in L4 separated by dark bands and photographed using a frame grabber for later analysis (see Fig. $1 A$ ). Interneurons were searched in layer $2 / 3$ above barrels of $250 \pm 70$ $\mu \mathrm{m}$ width $(n=64)$ using a water-immersion $40 \times 10.80$ NA objective and infrareddifferential interference contrast (DIC) microscopy (Dodt and Zieglgänsberger, 1990; Stuart et al., 1993). Somata of neurons in layer $2 / 3$ were selected for recording if an apical dendrite was not visible on close inspection (see Fig. 1B). This was the only criterion for the a priori selection of interneurons. Neurons in layer 4 were recorded in loose-patch mode (Feldmeyer et al., 1999 ) with a second pipette, and action potentials (APs) were elicited to test the connections. On average, 5-15 neurons were tested presynaptically before a connection was found. Then, the pipette was withdrawn and a new biocytincontaining pipette was inserted for whole-cell recording of the presynaptic L4 neuron. APs were elicited in the presynaptic neuron, and EPSPs were recorded in the postsynaptic neuron (see below, Synaptic stimulation). After recording, the pipettes were positioned above the slice at the position of the recorded cells, and the barrel pattern was again photographed using bright-field illumination.

Histological procedures. After recording, slices were fixed at $4^{\circ} \mathrm{C}$ for at least $24 \mathrm{~h}$ in 100 mм PB, pH 7.4, containing either $4 \%$ paraformaldehyde or $1 \%$ paraformaldehyde and $2.5 \%$ glutaraldehyde. Slices containing biocytinfilled neurons that were destined for lightmicroscopic analysis only, were processed using a modified protocol described previously (Lübke et al., 2000). Slices were incubated in $0.1 \%$ Triton X-100 solution containing avidinbiotinylated horseradish peroxidase (ABCElite; Camon); subsequently, they were reacted using 3,3-diaminobenzidine (DAB) as a chromogen under visual control until the dendritic and axonal arborization was clearly visible. To enhance staining contrast, slices were occasionally postfixed in $0.5 \% \mathrm{OsO}_{4}$ (for $30-45 \mathrm{~min}$ ). Slices were then mounted on slides, embedded in Mowiol (Clariant), and enclosed with a thin coverslip.

Reconstruction of neuronal morphologies. Subsequently, neurons were reconstructed with the aid of Neurolucida software (MicroBrightField) using an Olympus Optical BX50 microscope at a final magnification of $1000 \times$. The reconstructions provided the basis for the quantitative morphological analysis (see below). The pial surface of the slice was also reconstructed. The reconstruction was rotated in the plane of the slice such that the pial surface above the reconstructed neuron was horizontally aligned. Thus, the $x$-axis of the reconstruction was parallel to the pia in the plane of the slice, and the $y$-axis perpendicular to the pia in the plane of the slice. The reconstructions were read-in by the custom-made software Rembrandt II, and average length density maps of the presynaptic axons and the postsynaptic dendrites were constructed. Pairs were sorted according to the axonal projection type of the postsynaptic L2/3 interneuron. Axonal projection types were determined as reported previously (Helmstaedter et al. 2008a). The sample of L2/3 interneurons with monosynaptic input from L4 that is reported on in this study $(n=$ 46) was a subset of a sample of $L 2 / 3$ interneurons that has been subject to an extensive analysis of morphological and electrical features in accompanying studies ( $n=64$ ) (Helmstaedter et al., 2008a,b,c).

Electron microscopy. The procedure for correlated light and electron
B

$\mathrm{L} 2 / 3$

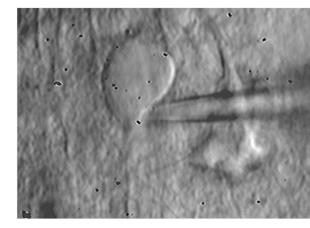

L4

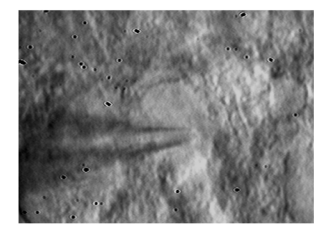

D

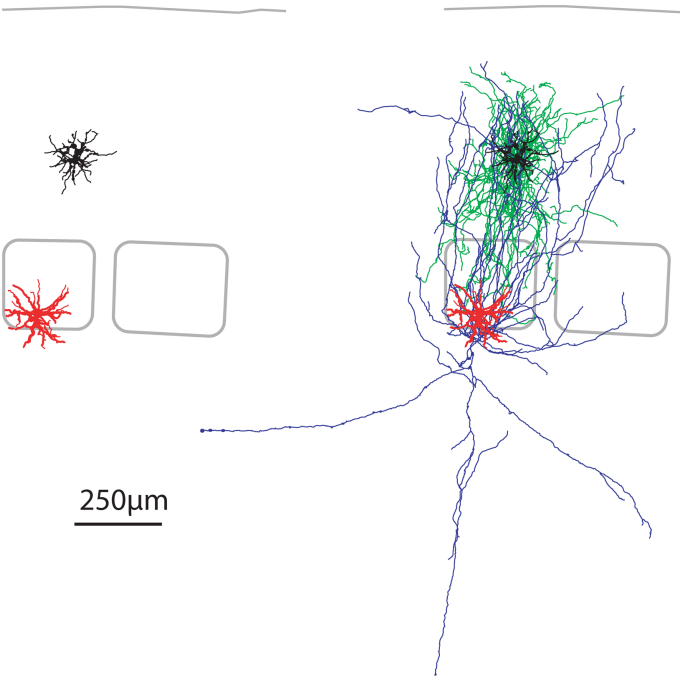

Figure 1. Paired whole-cell recordings of $L 4$ spiny neurons and $L 2 / 3$ interneurons. $A$, Bright-field image of the slice in the ecording chamber after the experiment. $\boldsymbol{B}$, DIC images at high magnification of the somata of the presynaptic and postsynaptic uron. C, Computer reconstruction of presynaptic (red) and postsynaptic (black) dendritic geometries. Barrel outlines are superimposed. D, Reconstruction of dendrites and axons of the presynaptic (L4 spiny neuron, red and blue) and postsynaptic (L2/3 interneuron, black and green) neurons.

microscopy has been described previously (Markram et al., 1997; Staiger et al., 2002). Briefly, in slices in which an electron microscopic verification of light microscopically identified contacts was intended, no detergent was used for visualizing biocytin. Instead, tissue was resectioned at $\sim 120 \mu \mathrm{m}$ thickness with a vibratome and freeze-thawed three times over liquid nitrogen to permeabilize membranes. After permanent staining with $\mathrm{DAB}$ and postosmification, the sections were dehydrated in an ascending series of ethanol and embedded in Durcupan ACM (Fluka). Finally, selected contacts were reembedded, trimmed, serially cut ultrathin (Leica UCT), mounted on Formvar-coated single-slot copper grids, and examined at the electron microscope (AB-912; LEO).

Synaptic stimulation. APs were elicited in $\mathrm{L} 4$ neurons by brief depolarizing current injections in whole-cell mode. One to $5 \mathrm{APs}$ (at 10,30, 40, or $100 \mathrm{~Hz}$ ) were elicited per sweep. The interval between sweeps was $\geq 30 \mathrm{~s}$ because smaller intervals resulted in a successive rundown of EPSP amplitudes. The long interval between sweeps allowed the recording of only low numbers of sweeps (typically 40-50). For analysis of unitary EPSP amplitudes, the EPSPs in response to the first presynaptic APs in all sweeps were analyzed. For analysis of synaptic short-term dynamics, the EPSPs in response to the first to third presynaptic APs were analyzed. This allowed an approximate classification of synapses as facilitating or depressing.

EPSP analysis. The analysis of EPSP amplitude, rise and decay times, APto-EPSP-onset latency, baseline voltage, noise and failures was performed as 
A

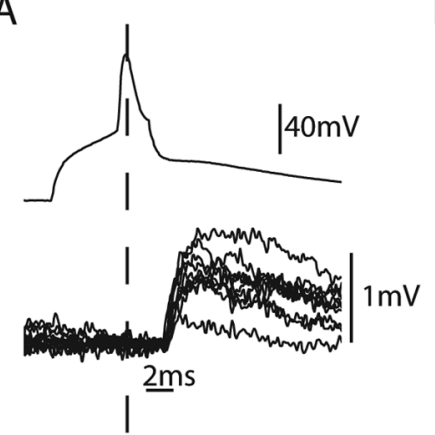

B

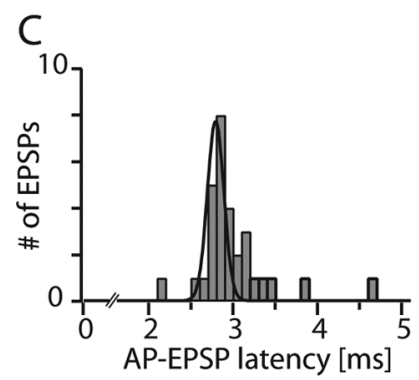

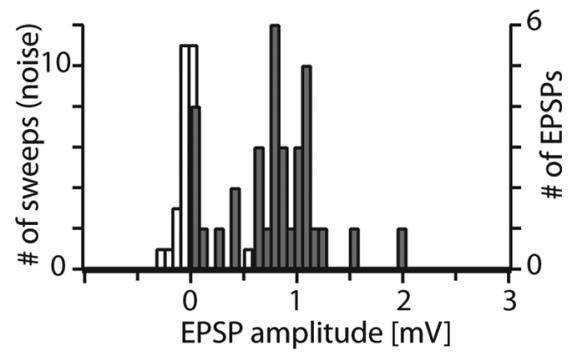

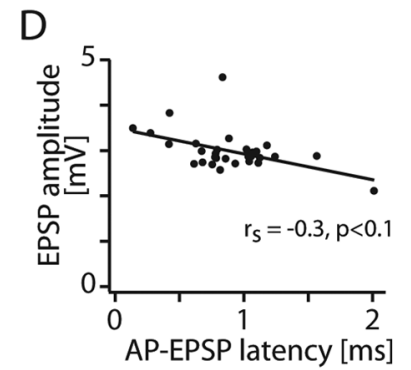

Figure 2. Properties of unitary EPSPs in a single connection. $A$, Presynaptic AP and overlay of 10 successive postsynaptic EPSPS from the pair shown in Figure 1. B, EPSP unitary amplitude histogram for this connection. White, noise; gray, sweeps including failures. C, AP-to-EPSP onset latency histogram. Note the narrow distribution (Gaussian fit with full width at half-maximum of 0.2 ms). D, Relationship between EPSP amplitudes and AP-EPSP latency in the single connection. There was no significant correlation.

A

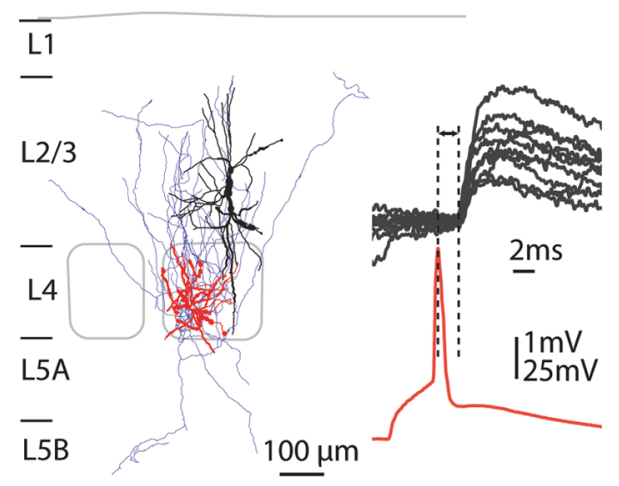

B

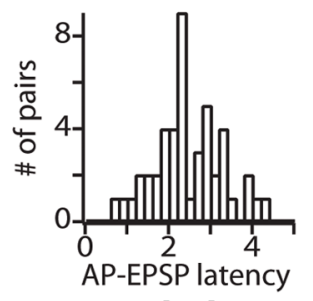

C

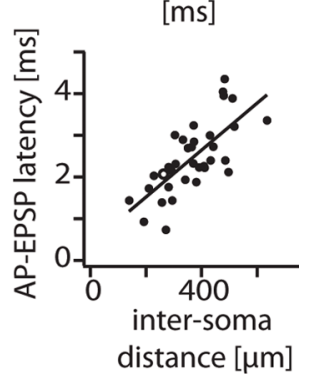

Figure 3. Latency of $L 4-t 0-L 2 / 3$ interneuron connections. $A$, Reconstruction of the dendrites and axon of the presynaptic $L 4$ neuron (red, blue) and the dendrite of the postsynaptic L2/3 interneuron (black). A presynaptic action potential (red trace) and 10 consecutive postsynaptic potentials are shown. $\boldsymbol{B}$, Latency histogram for all pairs (average, $2.4 \pm 0.8 \mathrm{~ms}$ ). C, Correlation between the distance of the presynaptic and postsynaptic somata and the latency between the peak of the AP and the onset of the EPSP $\left(r=0.7 ; p<10^{-5}\right.$; inverse slope, $\left.190 \mu \mathrm{m} / \mathrm{ms}\right)$. Open circle, Connection shown in $\boldsymbol{A}$.

described previously (Feldmeyer et al., 1999) using the custom-made software Pythagoras written in IGOR PRO (Wavemetrics).

Connection probability. The probability of finding a synaptically connected pair of a L4 spiny neuron and a L2/3 interneuron was assessed in three different ways: (1) the average number of presynaptic L4 neurons tested before a unitary synaptic connection was found for a given postsynaptic interneuron was recorded. On average, 5-15 presynaptic neurons had to be tested before a connection was found. However, this measure only partially reflects actual connectivity, because it can be assumed to be mostly biased by experimental constraints (search time, the slice cutting angle, and the positioning of the postsynaptic and presyn- aptic pipettes). (2) To detect also rare connections, up to 60 presynaptic neurons were tested in the loose-patch mode for a given postsynaptic neuron. If a monosynaptic connection was not found after this extensive searching, the L2/3 interneuron was, however, processed for morphological reconstruction in most cases. Therefore, we report putative connection rates for the different types of interneurons in Results [given the biases mentioned above under (1)]. (3) We also recorded synaptically connected pairs of L4 spiny neurons and L2/3 pyramidal neurons under similar experimental conditions. Qualitatively, connections between spiny neurons and L2/3 interneurons were more difficult to find than connections between spiny neurons and pyramidal neurons (judged by the same observer).

Because of the many constraints on judging connection probabilities from the experimental success rate, we report a more robust calculation of innervation probabilities based on morphological measures in Discussion.

Statistical analysis. The 11 groups of interneurons were tested for difference in synaptic properties [EPSP amplitude and paired-pulse (PP) ratio; multivariate ANOVA (MANOVA), $p<0.01$ ] (see Fig. 8). In addition, a bootstrapping test was made: The measured parameters were randomly assigned to group members, and the probability that random groups had proximities as the measured ones was calculated. This probability was $<0.05$.

For statistical testing of paired-pulse facilitation, the unitary EPSP amplitudes in response to the first $\mathrm{AP}$ in a train were tested against the unitary EPSP amplitudes in response to the second or third AP in a train (sampled over 10-100 sweeps).

For comparison of synaptic properties to the L4-L2/3 pyramidal neuron connections, data from the study by Feldmeyer et al. (2002) were used for statistical testing ( $t$ test of unitary EPSP amplitudes). The comparison of latency and intersoma distance of the presynaptic and postsynaptic neuron was done post hoc.

\section{Results Unitary EPSPs}

To investigate whether L2/3 interneurons are targets of monosynaptic input from layer 4, paired whole-cell voltage recordings were made in acute slices of P20-P29 rat barrel cortex. Figure $1 A$ shows a brightfield image of the recording configuration. Barrels in layer 4 were used to delineate the borders of cortical columns. Figure $1 B$ shows DIC images of a L2/3 interneuron (top) that received input from a $\mathrm{L} 4$ stellate neuron (bottom). Both were filled with biocytin and reconstructed. Figure 1, $C$ and $D$, depicts the reconstruction of the neurons shown in Figure $1 B$ and identifies the presynaptic neuron as a L4 spiny stellate neuron (dendrites, red; axon, blue), and the postsynaptic neuron as a L2/3 "local inhibitor" (dendrites, black; axon, green) [for definition of local inhibitors, see Helmstaedter et al. (2008a); for alternative nomenclature, see Discussion].

Figure $2 A$ shows the time course of the presynaptic AP (top 
trace) and evoked unitary EPSPs (bottom traces) from 10 consecutive sweeps in the cell pair shown in Figure 1. The EPSP amplitude of this pair was on average $0.78 \mathrm{mV}$ and showed a high variability $(0.78 \pm 0.45 \mathrm{mV})$ (Fig. $2 B$ ). The latencies of EPSP onset had a narrow distribution as shown in Figure $2 C$ for this connection ( $3.0 \pm 0.43 \mathrm{~ms}$; median, $2.88 \mathrm{~ms})$. The correlation between latency and EPSP amplitude in the same connection is shown in Figure 2D $(r=-0.48 ; p<0.01$; rank correlation, however, not significant).

Figure $3 A$ shows the morphology and recordings from another synaptically connected L4 spiny neuron-to-L2/3 interneuron pair with a unitary EPSP amplitude of $1.7 \pm 0.7 \mathrm{mV}$ and an AP-to-EPSP latency of $2.1 \pm 0.3 \mathrm{~ms}$. The distribution of AP-toEPSP onset latencies from 46 synaptically connected pairs is shown in Figure $3 B$ (average, $2.4 \pm 0.8 \mathrm{~ms}$ ). AP-to-EPSP onset latencies were highly correlated with the distance of the presynaptic and postsynaptic somata $\left(r=0.7 ; p<10^{-5}\right)$ (Fig. $3 C$ ) (inverse slope, $\sim 0.2 \mathrm{~m} / \mathrm{s}$ ).

Figure $4 A$ shows the distribution of EPSP unitary amplitudes from all recorded connections. The average efficacy of EPSPs in L2/3 interneurons evoked by APs in L4 spiny neurons was $1.2 \pm$ $1.1 \mathrm{mV}$. Consequently, L4 input to L2/3 interneurons is on average almost twofold more efficient than L4 input to $\mathrm{L} 2 / 3$ pyramidal cells (factor, 1.8; $p<0.005$ ) (cf. Feldmeyer et al., 2002). A high apparent somatic input resistance of L2/3 interneurons $\left(R_{\mathrm{in}}=\right.$ $260 \pm 140 \mathrm{M} \Omega)$ compared with $\mathrm{L} 2 / 3$ pyramidal cells $\left(R_{\text {in }}=73 \pm\right.$ $16 \mathrm{M} \Omega$ ) (Sarid et al., 2007) could account in part for the difference in unitary EPSP amplitudes. However, $R_{\text {in }}$ and EPSP amplitude were not correlated in connections with interneurons (Fig. $4 B$ ), indicating that $R_{\text {in }}$ alone cannot account for the differences in EPSP amplitudes.

Despite the high average efficacy, the L4-to-L2/3 interneuron connections had relatively high average failure rates of $19 \pm 18 \%$ (Fig. 4C).

EPSP latencies in the L4-to-L2/3 interneuron connections were slightly longer than EPSP latencies in L4-to-L2/3 pyramidal cell connections $(2.4 \pm 0.8$ vs $2.1 \pm 0.6 \mathrm{~ms} ; p<0.01)$ (cf. Feldmeyer et al., 2002). This could be attributable to a longer average intersoma distance of the L4-to-L2/3 interneuron pairs compared with L4-to-L2/3 pyramidal cell pairs $(380 \pm 110$ vs $310 \pm$ $100 \mu \mathrm{m} ; p<0.005)$. EPSP $20-80 \%$ rise times in the L4-to-L2/3 interneuron connection were $0.88 \pm 0.38 \mathrm{~ms}$, and average monoexponential decay time constants were $14 \pm 10 \mathrm{~ms}$. The time course of the EPSPs in L2/3 interneurons were thus similar to those of L2/3 pyramidal cells ( $p>0.4$ ).

\section{Synaptic short-term dynamics}

The short-term dynamics of the L4-to-L2/3 interneuron connections were investigated by stimulating the presynaptic L4 spiny neuron with trains of three to five APs (at $10 \mathrm{~Hz}$ ). Figure $5 \mathrm{~A}$ shows 20 consecutive recordings of EPSPs in a L2/3 interneuron, which displayed marked EPSP amplitude depression. The postsynaptic L2/3 interneuron of this connection had similarities to a basket cell with 10 primary dendrites, nonadapting firing pattern, small AP half-width, low input resistance, and a locally projecting axon ("group local 1" interneuron) (cf. Helmstaedter et al., 2008c) (for a detailed account of the identity of interneurons, see Fig. 8 and Discussion; for numbers, see legend to Fig. 5). The amplitude histograms for the EPSPs evoked by the first, second, and third AP in a train are shown in Figure $5 B$. In this connection, failures were absent even after the third AP ( 0 of 35).

In a different L4-L2/3 interneuron connection for which facilitating EPSPs were observed (Fig. 6), the failure rate for the first
A

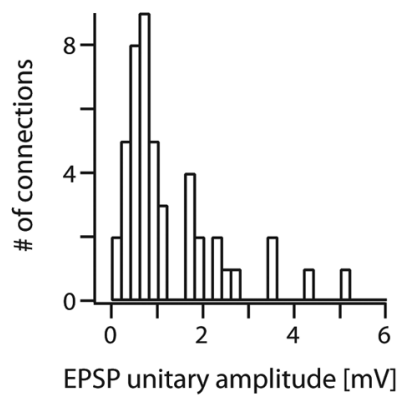

B

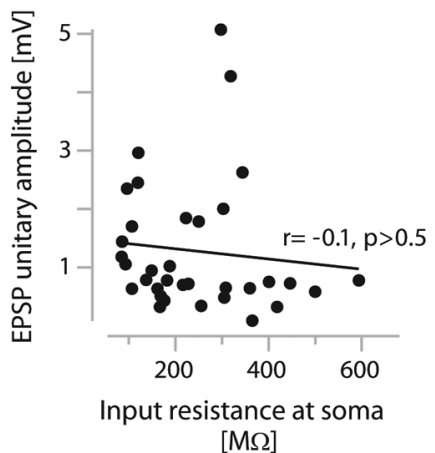

C

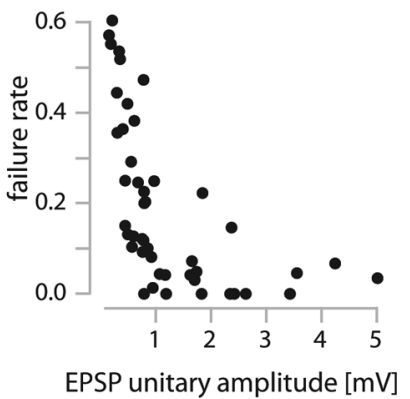

Figure 4. Unitary EPSP amplitudes in L4-to-L2/3 interneuron connections. $A$, Histogram of unitary EPSP amplitudes from all connections (average, $1.2 \pm 1.1 \mathrm{mV}$ ). $\boldsymbol{B}$, Relationship between unitary EPSP amplitude and apparent input resistance at the soma. There is no correlation, indicating that the high unitary amplitudes cannot be solely explained by higher input resistances. C, Relationship between failure rate and unitary EPSP amplitude.

AP was high (42\%). The postsynaptic L2/3 interneuron of this connection had similarities to a bitufted or bipolar neuron with two primary dendrites, a strongly adapting firing pattern, medium AP half-width, high input resistance, and a locally projecting axon ("group local 3" interneuron) (cf. Helmstaedter et al., 2008c) (for a detailed account of the identity of interneurons, see Fig. 8 and Discussion; for numbers, see legend to Fig. 6). Facilitation of the second EPSP was observed in $13 \%$ of the connections (Fig. 7A) [5 of 38 connections had significantly larger EPSP amplitudes in response to the second AP compared with the first $\mathrm{AP}(t$ test, $p<0.05)]$. Figure $7 A$ shows that facilitating connections had small unitary EPSP amplitudes $(0.6 \pm 0.5 \mathrm{mV})$. Only two of the connections with facilitation of the second EPSP showed significant facilitation also of the third EPSP (5\% of all connections; $p<0.05$ ) (Fig. $7 B$ ). A low release probability would account for the low efficacy of facilitating connections. Figure $7 C$ shows the high correlation of the paired-pulse ratio of the second 
A

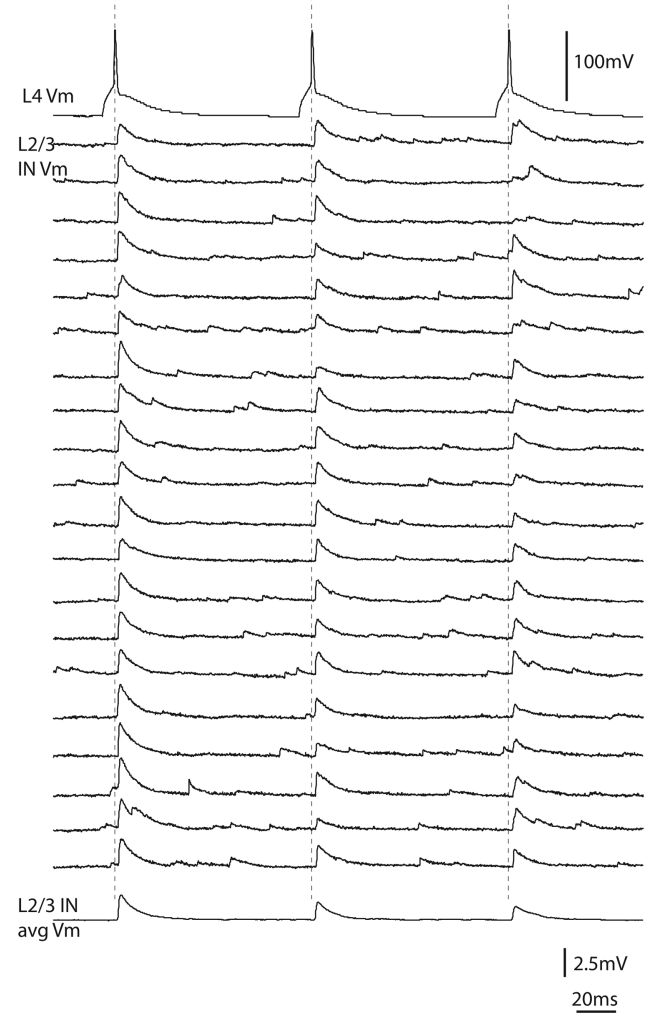

B
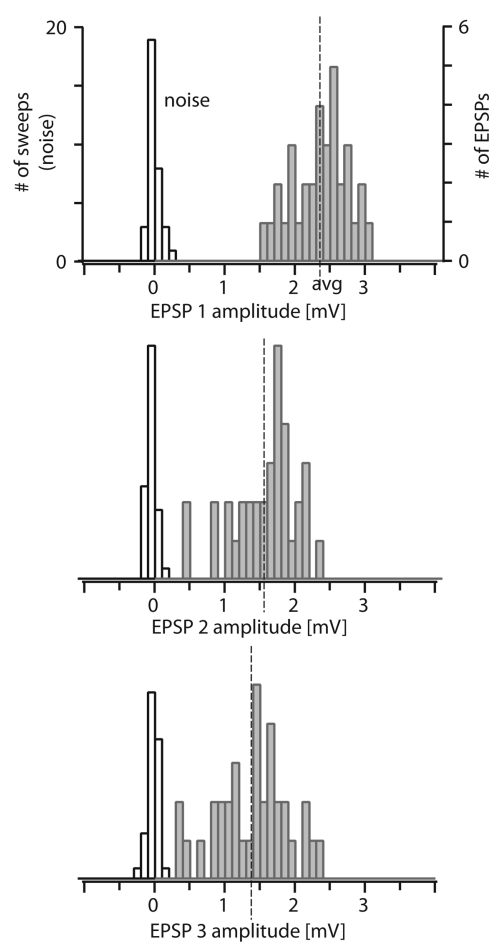

Figure 5. Paired-pulse depression in a L4-to-L2/3 interneuron connection. $A$, Train of three presynaptic APs at $10 \mathrm{~Hz}$ (top trace) and 20 consecutive sweeps that were on average depressing in amplitude (bottom trace). $\boldsymbol{B}$, Corresponding EPSP amplitude histograms for the first, second, and third EPSPs in a train. Note the narrow amplitude distribution of the first EPSP (top). White bars, Noise; gray bars, EPSPs. The postsynaptic L2/3 interneuron of this connection had similarities to a basket cell with 10 primary dendrites, nonadapting firing pattern (AP frequency adaptation ratio, $+3 \%)$, small AP half-width $(0.28 \mathrm{~ms})$, low input resistance $(96 \mathrm{M} \Omega$ ), and a locally projecting axon ( $83 \%$ of the axon extended to the home column; group local 1 interneuron) (cf. Helmstaedter et al., 2008c) (for a detailed account of the identity of interneurons, see Fig. 8 and Discussion).

to first EPSP with the failure rate of the first EPSP $(r=0.6 ; p<$ $0.001)$.

We then investigated the effect of successive presynaptic APs (evoked at 10,40,100 Hz) on the failure rate. The single failure rate in response to the first AP in a train was $19 \pm 18 \%$ averaged over all connections $(n=46)$ (see above) (Table 1, Fig. $4 C)$. The rate of double failures (i.e., postsynaptic response failures for both the first and second presynaptic AP in a train) was $2 \pm 5 \%$ (median, $0 \% ; n=29$ connections); the rate of triple failures was $1 \pm 3 \%$ (median, $0 \% ; n=29$ connections). Doublets or triplets of presynaptic APs (which occur in response to whisker stimulation in vivo) (cf. Brecht and Sakmann, 2002; de Kock et al., 2007) thus significantly reduced the probability of transmission failure in these connections.

\section{Target cell specificity of L4-to-L2/3 interneuron connections}

We first compared unitary EPSP properties of the interneuron "types" that have been defined based on their axonal projection patterns with reference to cortical columns (Helmstaedter et al. 2008a) (for a comparison to other interneuron classifications, see Discussion). Monosynaptic connections from layer 4 were found for 13 of 18 local inhibitors (i.e., L2/3 interneurons with axonal projections mostly confined to L2/3 of the home column) (compare Fig. $9 B$ ), 9 of 12 "lateral inhibitors" (i.e., L2/3 interneurons with axonal projections extending to neighboring columns) (see Fig. $10 \mathrm{~B}$ ), and 6 of 7 "translaminar inhibitors" (i.e., L2/3 inter- neurons with axonal projections to $\mathrm{L} 4$ and L5 of the home column) (see Fig. $11 B$ ). Unitary EPSP amplitudes and paired pulse ratios were not significantly different between interneuron types $(1.0 \pm 1.0,1.4 \pm$ $1.5,1.3 \pm 0.8 \mathrm{mV}$, respectively; $p>0.5$ ). "L1 inhibitors" (i.e., L2/3 interneurons with $>30 \%$ axonal projection to L1) (Helmstaedter et al., 2008a) did not receive monosynaptic input from layer 4 ( $n=0$ of 4 ). Synaptic properties for the axon types of interneurons are summarized in Table 1.

We then investigated whether synaptic properties of the L4-to-L2/3 interneuron connections were, however, specific for the groups of interneurons that have been defined based on a cluster analysis of axonal projection, dendritic parameters, and electrical excitability (Helmstaedter et al., 2008c) (for a comparison to other interneuron classifications, see Discussion). Figure 8 shows the distribution of the groups of interneurons with respect to PP ratio (EPSP 2/EPSP 1) and EPSP 1 unitary amplitude. "Interneuron groups" were significantly different in both synaptic properties (MANOVA, $p<0.01$; bootstrapping, $p<0.05)$. For example, one group of local inhibitors ("local 3") had very small EPSP amplitudes and showed PP facilitation (EPSP unitary amplitudes, $0.3 \pm 0.19 \mathrm{mV}$; PP ratios, $2 \pm 0.4$; EPSP 2 was significantly larger than EPSP 1 in these three connections, $p<0.05$ ). The dendrites of this group had similarities to bitufted or bipolar interneurons as described previously (Reyes et al., 1998) (for details, see Discussion). A second group of local inhibitors ("local 2") had small EPSP amplitudes but showed PP depression only $(0.59 \pm 0.21$ $\mathrm{mV} ; 0.7 \pm 0.18$, respectively). The dendrites and axons of this group had similarities to neurogliaform neurons (Tamás et al., 2003) (see Discussion). The groups of lateral inhibitors ("lateral 1," "lateral 3") had relatively large EPSP amplitudes ( $>1 \mathrm{mV})$ and displayed PP depression. Group lateral 1 neurons had similarities to large basket cells (Buhl et al., 1997; Wang et al., 2002) (see Discussion). The definition of these interneuron groups (Helmstaedter et al., 2008c) was performed independent of synaptic input properties. Thus, the significant differences with respect to EPSP properties allowed both an independent validation of the interneuron group definition and indicated target cell specificity of L4-to-L2/3 interneuron connections. For a relation of these results to other interneuron classifications, see Discussion.

\section{Innervation domains}

We also investigated the topology of innervation domains with reference to cortical columns for the L4-to-L2/3 interneuron connections. For the construction of innervation domains, 22 pairs were used with a complete reconstruction of the presynaptic and the postsynaptic neuron that allowed identification of the postsynaptic interneuron based on axon projection type.

Figure 9, $A$ and $B$, shows overlays of 10 L4-to-L2/3 interneuron connections with $\mathrm{L} 2 / 3$ local inhibitors as postsynaptic neu- 
rons. The reconstructions of L4-to-L2/3 interneuron connections with $\mathrm{L} 2 / 3$ lateral inhibitors are shown in Figure 10, and connections with $\mathrm{L} 2 / 3$ translaminar inhibitors are shown in Figure 11.

The average length density maps of the L4 spiny neuron axons (Figs. 9C1, 10C1, 11C1) were mostly confined to the home column and septum as reported previously (Lübke et al. 2000, 2003; Bender et al., 2003; Staiger et al., 2004), showing only some collaterals that project to neighboring columns (Figs. 10A, 11 A) (Staiger et al., 2004; Egger et al., 2008). However, there was no significant difference in the width of the $\mathrm{L} 4$ axon domain projecting to the three L2/3 inhibitor types (ANOVA, $p=0.07$ ). The projection domain of L4 spiny neurons to $\mathrm{L} 2 / 3$ interneurons was also not significantly different from the projection of L4 spiny neurons to L2/3 pyramidal neurons ( $p>0.5$, ANOVA) (supplemental Fig. 1, available at www. jneurosci.org as supplemental material).

We then explored the average innervation domains for local, lateral, and translaminar inhibitors (Figs. 9C3, 10C3, 11C3). Innervation domains were calculated as the product of postsynaptic dendritic and presynaptic axonal length density, quantifying the regions of high probability for establishing a synaptic contact. The innervation domains were mostly restricted to layer $2 / 3$ of the home column for all three types of interneurons. We then measured the total path length of L4 axons within a region of high innervation probability (this region was quantified as the isocontour containing $80 \%$ of the total L4-to-L2/3 interneuron innervation probability). On average, the innervation domain for the L4-to-L2/3 local inhibitors connection comprised $5.6 \mathrm{~mm}$ of L4 axonal path length and $1.7 \mathrm{~mm}$ of L2/3 interneuron dendritic path length (lateral inhibitors, 5.9 and $1.9 \mathrm{~mm}$; translaminar inhibitors, 5.0 and $1.6 \mathrm{~mm}$, respectively) (compare Table 2).

\section{Number and location of synaptic contacts}

Putative synaptic contacts were identified on the soma or dendrites of L2/3 interneurons in the light microscope. Figure 12 shows an example of a pair with two putative synaptic contacts (Fig. 12B,C). On average, L4 spiny neurons made $2.3 \pm 0.8$ putative contacts on $\mathrm{L} 2 / 3$ interneuron dendrites (range, $1-3 ; n=7$ ) at a distance of $77 \pm 44 \mu \mathrm{m}$ (range, $36-172$ $\mu \mathrm{m} ; n=7)$. The number of putative contacts per connection was thus significantly smaller than for the L4-to-L2/3 pyramidal neuron connection (range, $4-5 ; n=13$ ) (cf. Feldmeyer et al., 2002) but similar to previously reported numbers in cat visual cortex (Buhl et al., 1997). For three pairs, light microscopically identified putative synaptic contacts were verified in the electron microscope. Figure 12,

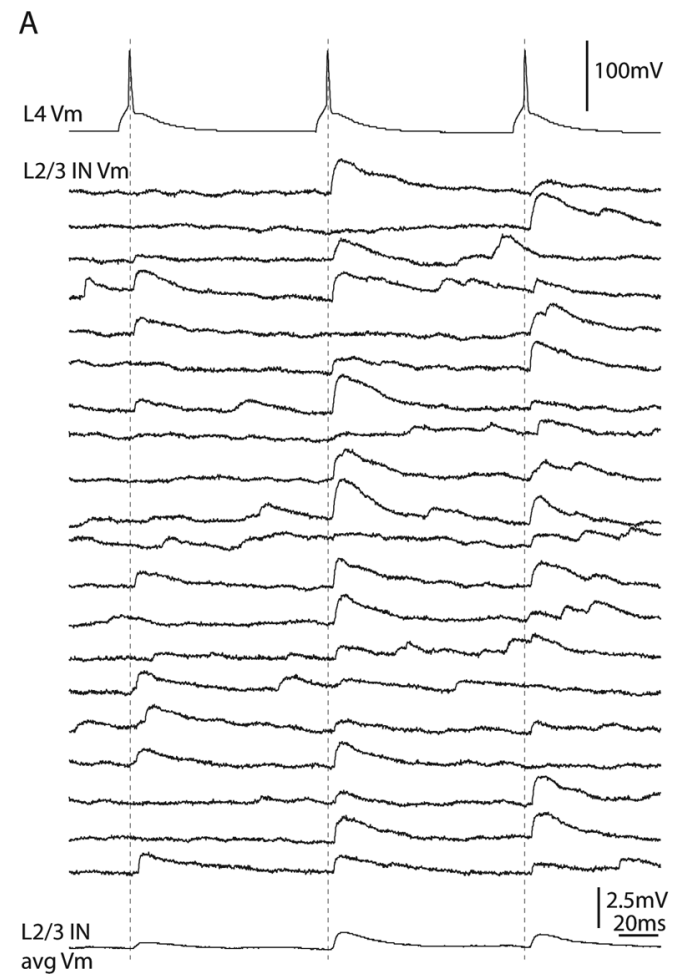

B
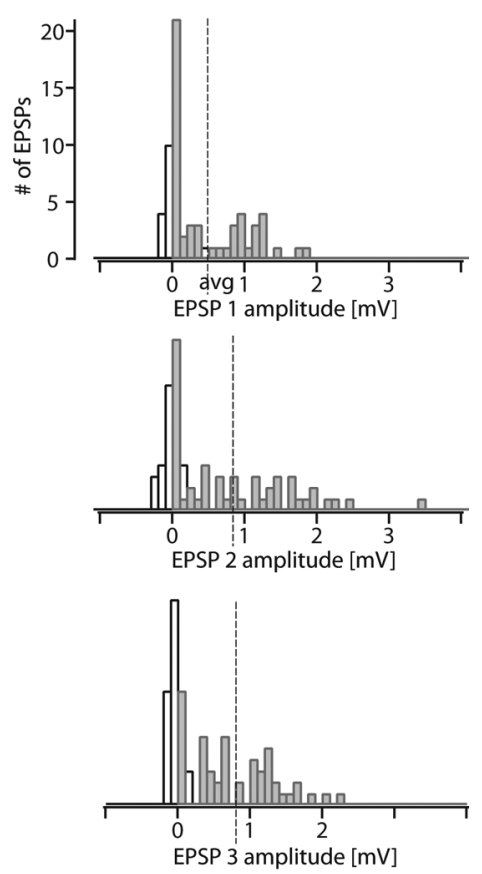

Figure 6. Paired-pulse facilitation in a L4-to-L2/3 IN connection. $A$, Train of three presynaptic APs at $10 \mathrm{~Hz}$ (top trace) and 20 consecutive sweeps that were on average facilitating in amplitude (bottom trace). $\boldsymbol{B}$, Corresponding EPSP amplitude histograms for the first, second, and third EPSP in a train. Note the marked decrease in failure counts for the third EPSP compared with the first EPSP. The postsynaptic L2/3 interneuron of this connection had similarities to a bitufted or bipolar neuron with two primary dendrites, a strongly adapting firing pattern (AP frequency adaptation ratio, $-93 \%$ ), medium AP half-width $(0.47 \mathrm{~ms})$, high input resistance $(300 \mathrm{M} \Omega$ ), and a locally projecting axon ( $91 \%$ of the axon extended to the home column; group local 3 interneuron) (cf. Helmstaedter et al., 2008c) (for a detailed account of the identity of interneurons, compare Fig. 8 and Discussion).
A

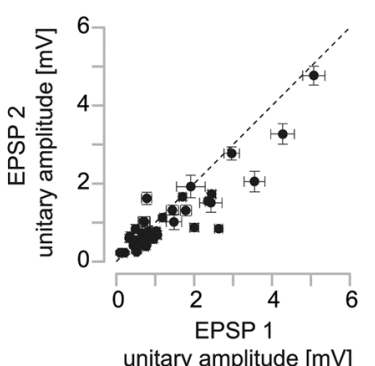

B

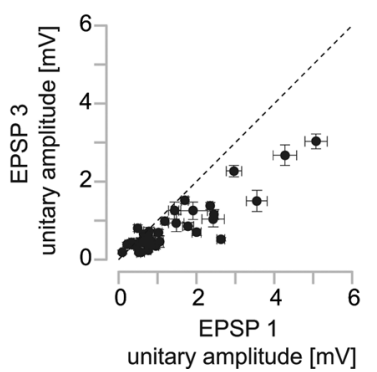

C

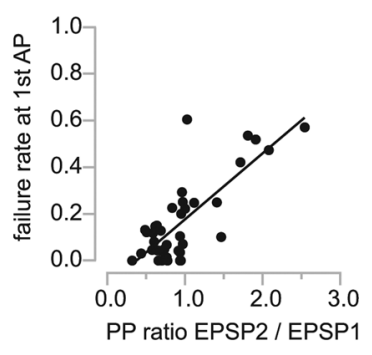

Figure 7. Paired-pulse properties of L4-to-L2/3 interneuron connections. $A$, Comparison of the second and first EPSPs evoked by a train of presynaptic APs at $10 \mathrm{~Hz}$. Note that connections with paired-pulse facilitation had small EPSP amplitudes. For five connections, the second EPSP amplitude was significantly larger than the first EPSP amplitude $(p<0.05)$. B , Comparison of the third and first EPSPs. Only two of five connections that showed facilitation of the second EPSP also showed significant facilitation of the third EPSP. Error bars are SEM in $\boldsymbol{A}$ and $\boldsymbol{B}$. C, Correlation between failure rate and PP ratio $(r=0.6 ; p<0.001)$. Connections with paired-pulse facilitation had a high failure rate.

$C$ and $D$, shows the electron microscopic images of the contacts located on varicose swellings of second-order dendrites (Fig. $12 A, B)$. Six of 10 putative synaptic contacts could be verified in the EM. The remaining four either were lost during tissue preparation or were uninterpretable because of parallel orientation of synaptic cleft and cutting orientation.

\section{Discussion}

\section{Signal flow in a cortical column}

The scheme in Figure 13 illustrates the signal flow between layer 4 and layer $2 / 3$ of a cortical column based on data from paired 
Table 1. Synaptic properties of L4-to-L2/3 interneuron connections

\begin{tabular}{|c|c|c|c|c|c|c|}
\hline & $\begin{array}{l}\text { Unitary EPSP } \\
\text { amplitude (mV) (\%) }\end{array}$ & $\begin{array}{l}\text { AP-EPSP latency } \\
\text { (ms) (\%) }\end{array}$ & $\begin{array}{l}20-80 \% \text { rise } \\
\text { time (ms) (\%) }\end{array}$ & $\begin{array}{l}\text { EPSP decay time } \\
\text { constant (ms) (\%) }\end{array}$ & $\begin{array}{l}\text { Failure rate } \\
(\%)\end{array}$ & PP ratio (\%) \\
\hline \multicolumn{7}{|l|}{ Types } \\
\hline Local inhibitors $(n=10)$ & $0.96 \pm 97$ & $2.5 \pm 35$ & $0.89 \pm 35$ & $15 \pm 55$ & $0.20 \pm 100$ & $0.99 \pm 66$ \\
\hline Lateral inhibitors $(n=8)$ & $1.4 \pm 107$ & $2.2 \pm 27$ & $0.79 \pm 64$ & $8.5 \pm 37$ & $0.13 \pm 141$ & $0.92 \pm 43$ \\
\hline Translaminar inhibitors $(n=6)$ & $1.3 \pm 67$ & $2 \pm 44$ & $1.1 \pm 33$ & $14 \pm 29$ & $0.13 \pm 146$ & $1 \pm 62$ \\
\hline L1 inhibitors $(n=4)$ & Not connected & & & & & \\
\hline \multicolumn{7}{|l|}{ Groups } \\
\hline Lateral $1(n=3)$ & $1.2 \pm 15$ & $2.1 \pm 7$ & $0.42 \pm 23$ & $6.3 \pm 33$ & $0.028 \pm 86$ & $0.84 \pm 20$ \\
\hline Local $2(n=5)$ & $0.59 \pm 35$ & $2.3 \pm 35$ & $0.85 \pm 30$ & $13 \pm 48$ & $0.17 \pm 80$ & $0.7 \pm 26$ \\
\hline Local $3(n=3)$ & $0.3 \pm 66$ & $3 \pm 38$ & $1.2 \pm 6$ & $22 \pm 45$ & $0.51 \pm 15$ & $2 \pm 22$ \\
\hline All groups and ungrouped ( $n=46)$ & $1.2 \pm 88$ & $2.4 \pm 34$ & $0.88 \pm 43$ & $14 \pm 73$ & $0.19 \pm 96$ & $0.96 \pm 50(n=38)$ \\
\hline
\end{tabular}

Data are sorted for the types of axonal projection of the postsynaptic interneurons (top rows) (types were defined by the axonal projection with reference to cortical columns) (Helmstaedter et al., 2008a), for the groups of L2/3 interneurons with at least three samples (bottom rows), and for the whole sample. Values are given as mean \pm coefficient of variation to allow a comparison of the homogeneity of parameters for types, groups, and the whole sample.
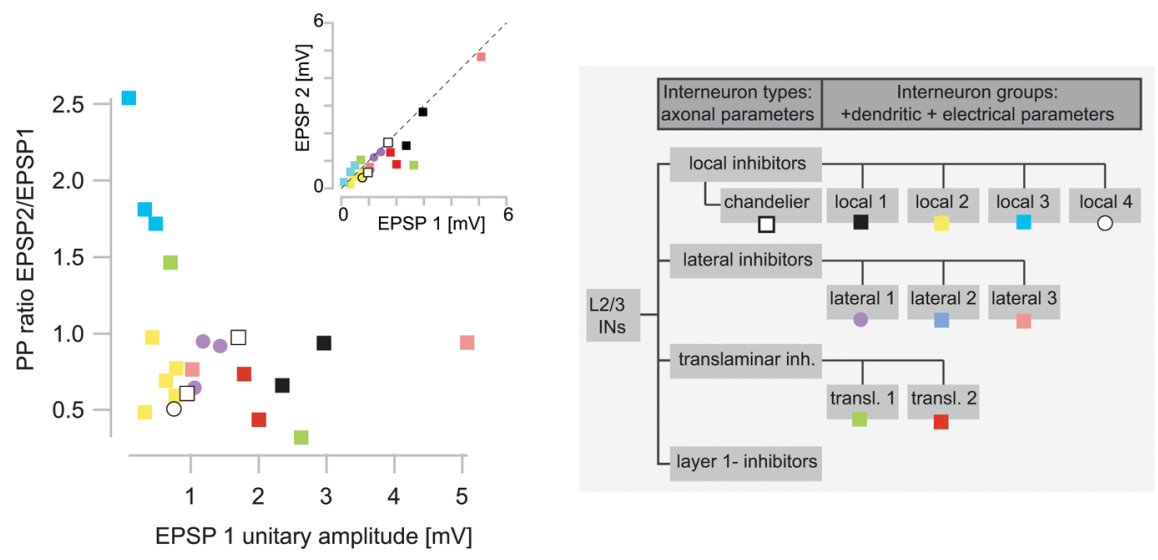

Figure 8. Relationship between synaptic properties and groups of postsynaptic interneurons. Relationship of PP ratio and EPSP amplitude to groups of interneurons as defined by a cluster analysis of axonal, dendritic, and electrical excitability parameters (Helmstaedter et al., 2008c) (color coded). Interneurons belonging to the same group were close in this parameter space (groups translaminar 2, lateral 1, local 1, local 2, local 3, chandelier neurons). Only three groups with two samples each were less similar (groups translaminar 1, lateral 3). Group lateral 2 neurons and L1 inhibitors did not receive input from layer 4 ( 0 of 1, 0 of 4 respectively). The difference of interneuron groups with respect to synaptic properties was significant (MANOVA, $p<0.01$; bootstrapping, $p<0.05$ ) (see Materials and Methods). The three group local 3 interneurons showed significant PP facilitation each ( $t$ test, $p<0.05$ ). Note that the synaptic properties of types of interneurons just separated by their axonal projection were not different $(p>0.5)$ (data not shown). The gray inset shows the classification of interneurons into types and groups as suggested by unsupervised cluster analysis (Helmstaedter et al., 2008c). For a comparison to other interneuron classifications, see Discussion.

recordings (Feldmeyer et al., 1999, 2002). An AP in a L4 spiny neuron elicits EPSPs in neighboring L4 spiny neurons of the same column (Fig. 13A, connection 1) and EPSPs in L2/3 pyramidal cells with an average efficacy of $0.7 \mathrm{mV}$ (Feldmeyer et al., 2002) (Fig. 13A, connection 2). Assuming approximately linear superposition of EPSPs in L2/3 pyramidal neurons, $\sim 30$ unitary EPSPs evoked from presynaptic L4 spiny neurons are required within a time window of $\sim 10 \mathrm{~ms}$ for eliciting an AP in a L2/3 pyramidal neuron (Lübke et al., 2003). However, because APs in L4 spiny neurons are not perfectly time-locked but display considerable jitter (Brecht and Sakmann, 2002), the total number of APs in L4 spiny neurons required to generate APs in L2/3 pyramidal neurons is likely to be higher.

Concomitantly, APs in L4 spiny neurons also elicit EPSPs in L2/3 interneurons (Fig. 13A, connection 3 ) with an average efficacy of $1.2 \mathrm{mV}, \sim 1.8$ times the size of unitary EPSP evoked by L4 spiny neurons in L2/3 pyramidal cells. Thus, because of the high efficacy, only $\sim 15$ unitary EPSPs evoked from presynaptic L4 spiny neurons are required within a time window of $\sim 10 \mathrm{~ms}$ for eliciting an AP in a L2/3 interneuron. Connections from L4 to
L2/3 interneurons were previously suggested using photostimulation in layer 4 (Dantzker and Callaway, 2000).

$\mathrm{L} 2 / 3$ interneurons project to pyramidal cells within layer 2/3 (Fig. 13A) (Reyes et al., 1998; Kapfer et al., 2007). Assuming that L4 spiny neurons project to both L2/3 pyramidal cells and to L2/3 interneurons, which in turn project to $\mathrm{L} 2 / 3$ pyramidal cells, the APs in a L4 spiny cell in response to a sensory stimulus will eventually evoke both glutamate and GABA release onto L2/3 pyramidal cells via this translaminar circuit. The minimum delay for the IPSPs in L2/3 pyramidal cells will then be governed by the time in which an AP is generated in the L2/3 interneurons, the axonal conduction time, and the synaptic delay in the L2/3 interneuronto-L2/3 pyramidal cell connection. Together, this amounts to an estimate of 4-10 ms minimum delay between the onset of the evoked EPSP in the L2/3 pyramidal cell (via connection 2) (Fig. 13A) and an IPSP in the $\mathrm{L} 2 / 3$ pyramidal cell generated by a $\mathrm{L} 2 / 3$ interneuron. It remains, however, to be elucidated which groups of $\mathrm{L} 2 / 3$ interneurons that are excited by L 4 spiny cells also project to $\mathrm{L} 2 / 3$ pyramidal cells.

Figure $13 B$ schematically summarizes the average properties of EPSPs evoked by an AP in a L4 spiny neuron in other L4 spiny neurons, L2/3 pyramidal cells, and L2/3 interneurons (dashed, dotted, and black traces, respectively). The delay between the AP and the EPSPs was twice as long for the translaminar connections ( 2.4 and 2.1 vs $0.9 \mathrm{~ms}$ ). The AP-to-EPSP delay was not different in L2/3 pyramidal cells and L2/3 interneurons. However, we observed a strong correlation between AP-to-EPSP latency and the distance of the presynaptic and postsynaptic somata (compare Fig. 3C) (Feldmeyer et al., 2002). This correlation could be an effect of axonal path length. Our data yielded an estimate of 0.2 $\mathrm{m} / \mathrm{s}$ axonal conduction velocity. This was in the range of conduction velocities reported for the unmyelinated Schaffer collaterals (0.1-0.5 m/s) (Andersen et al., 1978; Grinvald et al., 1982; Soleng et al., 2003; Meeks et al., 2005).

Two groups of L2/3 interneurons project to layers 4 and $5 \mathrm{~A}$ within a column (groups "translaminar 1" and "translaminar 2") (Helmstaedter et al., 2008a,c). APs elicited in these interneurons by excitatory input from layer 4 would thus inhibit neurons in 
layer 4 and 5A, also with a minimum delay of 4-10 ms compared with the direct excitatory input to these neurons from layer 4. The monosynaptic input from L4 spiny neurons to L5A pyramidal cells (Feldmeyer et al., 2005; Schubert et al., 2006) could thus be complemented by an inhibitory feedback via those $\mathrm{L} 2 / 3$ interneurons that are the targets of L4 spiny neurons.

\section{Estimates of divergence and convergence in the L4-to- $\mathrm{L} 2 / 3$ interneuron connection}

To estimate the number of synaptic connections made by a single L4 spiny neuron onto $\mathrm{L} 2 / 3$ interneurons ("divergence"), we measured the length of L4 axon extended in a region of high innervation probability for $\mathrm{L} 2 / 3$ interneurons. Assuming an approximate bouton density of $0.4 / \mu \mathrm{m}$ for the L4 axon (Lübke et al. 2003), the L4-to-L2/3 interneuron innervation domain contained on average 2200 L4 spiny cell boutons. Furthermore, assuming that $\sim 20 \%$ of the boutons were contacting inhibitory neurons, a single L4 neuron could be expected to establish synaptic connections with $190 \mathrm{~L} 2 / 3$ interneurons $(5500 \mu \mathrm{m} \times$ 0.4 boutons $/ \mu \mathrm{m} \times 20 \% / 2.3$ contacts per connection; divergence). Finally, if layer 4 comprised $\sim 3000-4000$ neurons (Beaulieu, 1993) (for discussion, see Lübke et al., 2003) and L2/3 comprised $\sim 600-800$ interneurons $(=20 \%$ of $3000-4000$ neurons), in a rough approximation, a single $\mathrm{L} 2 / 3$ interneuron would be contacted by 1000 (range, $710-1270$ ) L4 spiny neurons ("convergence": 24-32\%). The convergence estimate was larger than the estimate derived from the experimental success rate (on average, 5-15 L4 neurons had to be tested before a synaptic connection was found for a given L2/3 interneuron, corresponding to a convergence of 7-20\%; this measure is however sensitive to several experimental biases) (see Materials and Methods).

During a whisker stimulus, $\sim 0.1-0.4$ APs per stimulus have been measured in vivo (Brecht and Sakmann, 2002; de Kock et al. 2007). Thus, after a whisker stimulus, unitary EPSPs evoked by $100-400$ APs can be expected to converge on a L2/3 interneuron. Given the high efficacy of the connections $(1.2 \mathrm{mV})$, a nearsynchronous input can be expected to yield suprathreshold activation of $\mathrm{L} 2 / 3$ interneurons. This first-order calculation therefore predicts effective and strong activation of L2/3 interneurons by the neocortical input layer 4 in barrel cortex after a whisker deflection (this calculation predicts suprathreshold activation even if the proportion of L4 boutons onto interneurons in L2/3 was actually smaller than the estimated $20 \%$ ). AP rates of L2/3 pyramidal neurons are low (Brecht et al., 2003; de Kock et al., 2007), and the efficient activation of $\mathrm{L} 2 / 3$ interneurons that project to $\mathrm{L} 2 / 3$ pyramidal neurons could contribute to the low AP response of L2/3 pyramidal neurons measured in vivo.

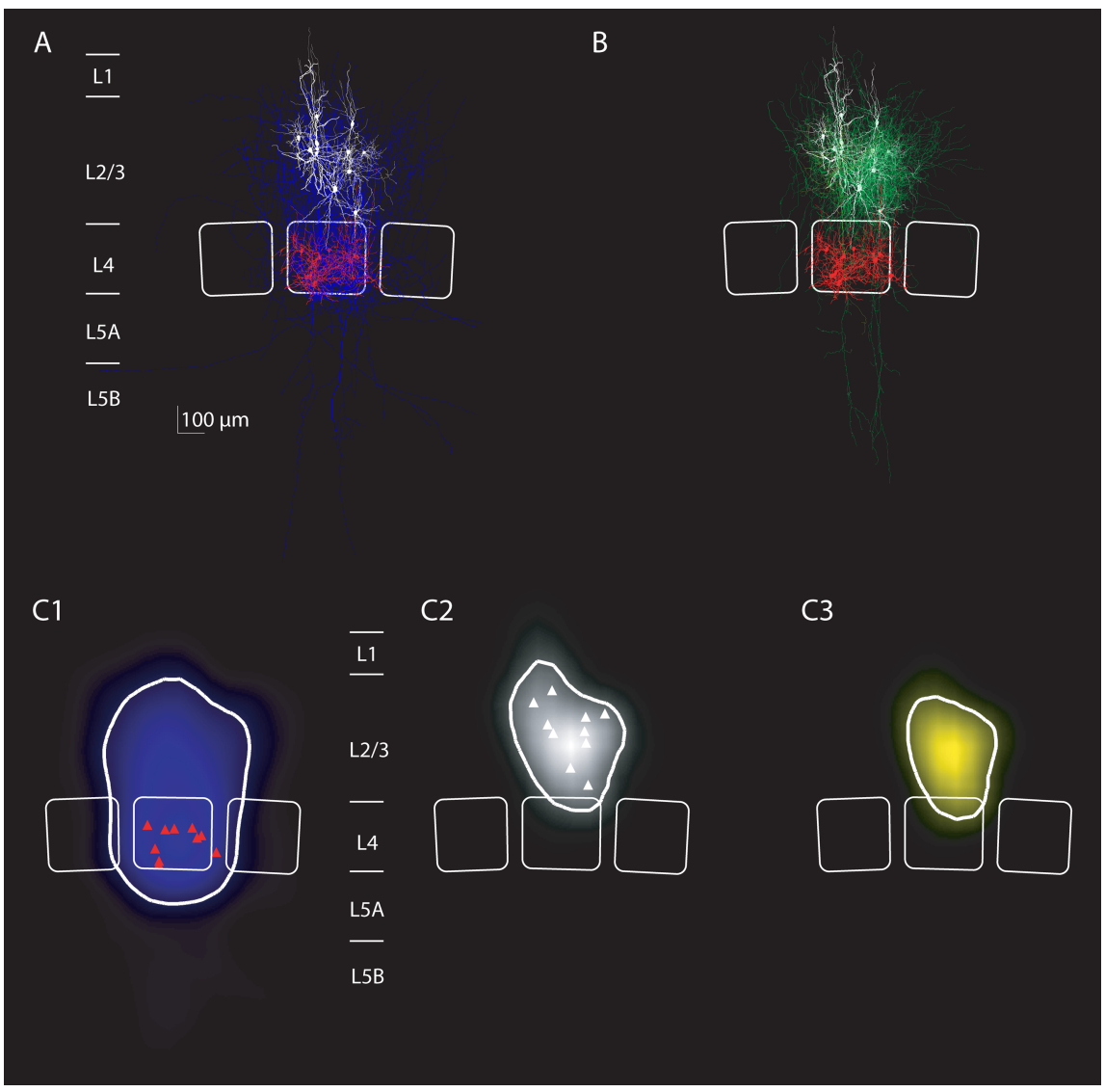

Figure 9. Average projections and innervation domains of $L 4$ spiny neurons projecting to $L 2 / 3$ interneurons of the local inhibitor type. $A$, Overlay of all reconstructions of $L 4$ spiny neurons that were synaptically connected to $L 2 / 3$ interneurons with ocal axonal projection of the postsynaptic interneurons ( $n=10$ pairs with sufficient staining of the axon of $L 4$ spiny neurons). in of 4 spiny neurons are in red, their axons are in blue, and dendrites of $L 2 / 3$ interneurons are in white. Average barrel utlines that were calculated from the barrel outlines of all 10 experiments are superimposed (white lines). B, Overlay of all reconstructions of L2/3 interneurons with local axonal projections (dendrites, white; axon, green) that received input from $L 4$ spiny hibitors. The isodensity line containing $90 \%$ of the axon is shown (thick white line). L4 soma locations are indicated (red . probability computed as the product of the presynaptic axonal density map (C1) with the postsynaptic dendritic density map (C2). The isoprobability contour containing $90 \%$ of the total probability is shown (white line) and defines the innervation domain of L2/3 local inhibitors from L4 spiny neurons.

\section{Target cell specificity of L4 spiny neuron axon boutons}

The axonal projection domain of L4 spiny neurons that innervate L2/3 interneurons overlaps with the axonal projection domain of L4 spiny neurons that innervate L2/3 pyramidal cells (see Results) (Fig. 13A, connections 2 and 3 ). It is therefore suggestive to assume that all or a substantial fraction of the population of L4 spiny neurons targets both $\mathrm{L} 2 / 3$ interneurons and $\mathrm{L} 2 / 3$ pyramidal cells. We showed here that the L4-to-L2/3 interneuron connection had specific properties (EPSP amplitudes and PP ratios) for different groups of postsynaptic L2/3 interneurons. Also, we found that the synaptic properties of the L4 projection to L2/3 interneurons were on average different from the synaptic properties of the L4 projection to L2/3 pyramidal neurons (Feldmeyer et al., 2002). Together, this implies target cell specificity of glutamate release from translaminar L4 spiny neuron axon boutons. Previously, target cell specificity has been found for local intralaminar connections in layer 2/3 (Reyes et al., 1998; Koester and Johnston, 2005), layer 4 (Beierlein et al., 2003), and layer 5 (Markram et al., 1998) with intersomatic distances of $\sim 50-$ 


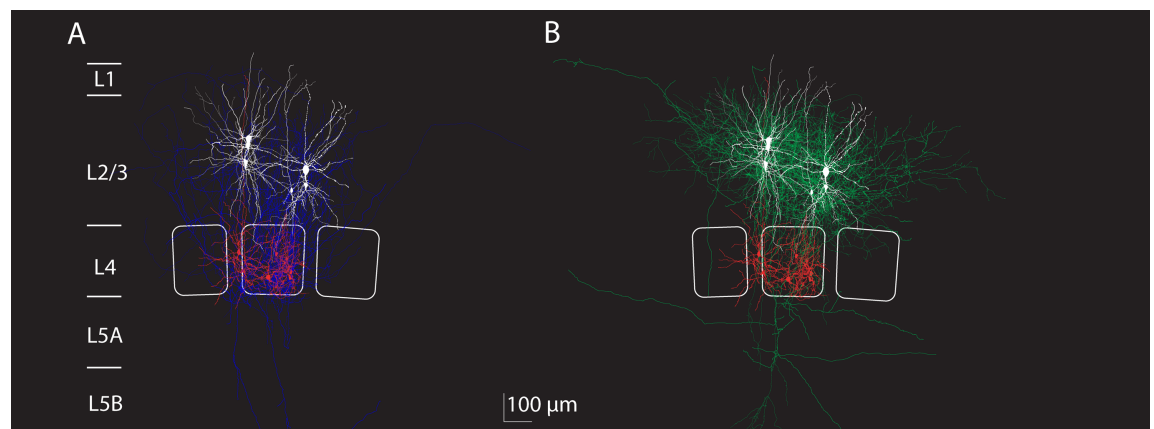

C1

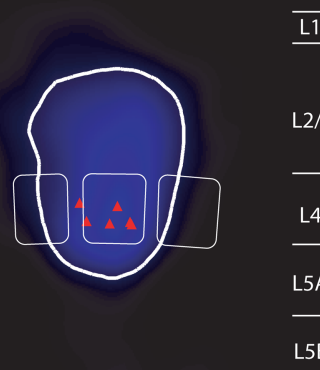

$\mathrm{C} 2$

$L 2 / 3$

L4

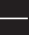

L5A

5 B
C3

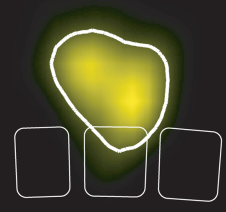

$\mathrm{L} 2 / 3$ interneurons as presented in accompanying studies (interneuron groups) (Helmstaedter et al., 2008a,b,c). The definition of interneuron groups can be related to interneuron classifications frequently used in the literature: "Martinotti" cells, "neurogliaform" cells, "basket" cells, "bitufted/bipolar" cells, and "chandelier" cells. Martinotti cells have been described as interneurons with extensive projections to L1 (Martinotti, 1889; Ramón y Cajal, 1904; Wang et al., 2004). In our sample, L1 inhibitors did not receive monosynaptic input from L4 (0 of 4). Neurogliaform cells were described as neurons with very small dendritic and axonal trees (Ramón y Cajal, 1904; Jones, 1984; Kawaguchi and Kubota, 1997; Tamás et al., 2003). In our sample, interneuron group local 2 had similarities to neurogliaform neurons; all group local 2 interneurons received monosynaptic input from L4 with small and depressing EPSP amplitudes (Fig. 8). Basket cells have been described as interneurons with small AP half-width, high AP firing rates, low somatic input resistance, multipolar dendritic trees, and extensive local axonal arborizations (Ramón y Cajal, 1904; MarínPadilla, 1969; Somogyi et al., 1983; Wang et al., 2002). Group lateral 1 could be described as "large basket cells" with large multipolar dendrites and significant axonal projection to neighboring columns (Helmstaedter et al., 2008c); this group received depressing monosynaptic input from L4 (Fig. 8). Bitufted or bipolar interneurons in $\mathrm{L} 2 / 3$ have been described as in-

Figure 10. Average projections and innervation domains of $L 4$ spiny neurons projecting to $L 2 / 3$ interneurons of the latera inhibitor type. $A$, Overlay of all reconstructions of $L 4$ spiny neurons that were synaptically connected to $L 2 / 3$ interneurons with lateral axonal projection of the postsynaptic interneurons ( $n=6$ with sufficient staining of the axon of $L 4$ spiny neurons). $B$ Overlay of reconstructions of $L 2 / 3$ interneurons with lateral axonal projections (color code is as in Fig. 9). (1-C3, Axonal density maps, dendritic density maps, and innervation domain of L4-to-L2/3 lateral inhibitor connections. Note that also the dendritic domain of lateral inhibitors is larger than the dendritic domain of local inhibitors (compare Fig. 9). The innervation domain is, however, mostly confined to lower layer $2 / 3$.

$150 \mu \mathrm{m}$. The present data demonstrate target cell specificity in a translaminar connection with intersomatic distances of $200-600 \mu \mathrm{m}$.

The targets of L4 spiny neurons examined so far by pair recordings are (1) excitatory spiny neurons in L4 (Feldmeyer et al., 1999), (2) excitatory pyramidal cells in layer $2 / 3$ (Feldmeyer et al., 2002), (3) excitatory pyramidal cells in layer 5A (Feldmeyer et al., 2005), (4) morphologically not-identified fast spiking and low-threshold spiking interneurons in layer 4 (Beierlein et al., 2003), and finally nine groups of interneurons in layer $2 / 3$ (this study) that are mainly classified by their projection patterns (Helmstaedter et al., 2008a). All projections of L4 spiny neurons to excitatory neurons examined so far had low failure rates and paired-pulse depression. The projections of L4 neurons to inhibitory neurons in layer 4 (Beierlein et al., 2003) and layer 2/3 (this study) showed in contrast a heterogeneity in release parameters. This heterogeneity in release parameters most likely reflects target cell specificity, and not different developmental stages of inhibitory and excitatory cells at the age that we investigated (P20 P29), as was suggested for early postnatal development in mice (Chattopadhyaya et al., 2004; Di Cristo et al., 2004).

\section{Comparison with other interneuron classifications}

We related the data on synaptic connections from L4 spiny neurons to L2/3 interneurons to a concomitant analysis of axonal, dendritic, and intrinsic electrical properties of the postsynaptic terneurons with a polar dendritic tree, a narrow axonal projection, and adapting firing patterns (Fairén et al., 1984; Tamás et al., 1997; Reyes et al., 1998). Group local 3 interneurons matched some of these criteria of bitufted neurons. Synaptic input from L4 to these group local 3 interneurons was facilitating (Fig. 8, Table 1). Previous studies have shown that bitufted interneurons in $\mathrm{L} 2 / 3$ received facilitating monosynaptic input from $\mathrm{L} 2 / 3$ pyramidal neurons (Reyes et al., 1998). Finally, two chandelier neurons in the sample also received monosynaptic input from L4 (compare Fig. 8).

\section{Outlook}

To achieve a detailed mechanistic model of cortical columns with single-cell resolution, the main connectivity patterns within and across cortical layers have to be established. One missing link at present is the projection from $\mathrm{L} 2 / 3$ interneurons to $\mathrm{L} 2 / 3$ pyramidal cells specified for the different groups of $L 2 / 3$ interneurons. Finally, in vivo recordings of L2/3 interneurons from the different groups after physiological stimulation must complement the data from in vitro paired recordings. This will eventually allow simulating the signal flow through a column, initiated by a natural stimulus like a whisker deflection.

\section{References}

Agmon A, Connors BW (1991) Thalamocortical responses of mouse somatosensory (barrel) cortex in vitro. Neuroscience 41:365-379. 
Andersen P, Silfvenius H, Sundberg SH, Sveen O, Wigström H (1978) Functional characteristics of unmyelinated fibres in the hippocampal cortex. Brain Res 144:11-18.

Armstrong-James M, Fox K, Das-Gupta A (1992) Flow of excitation within rat barrel cortex on striking a single vibrissa. J Neurophysiol 68:1345-1358.

Beaulieu C (1993) Numerical data on neocortical neurons in adult rat, with special reference to the GABA population. Brain Res 609:284-292.

Beierlein M, Gibson JR, Connors BW (2003) Two dynamically distinct inhibitory networks in layer 4 of the neocortex. J Neurophysiol 90:2987-3000.

Bender KJ, Rangel J, Feldman DE (2003) Development of columnar topography in the excitatory layer 4 to layer $2 / 3$ projection in rat barrel cortex. J Neurosci 23:8759-8770.

Brecht M, Sakmann B (2002) Dynamic representation of whisker deflection by synaptic potentials in spiny stellate and pyramidal cells in the barrels and septa of layer 4 rat somatosensory cortex. J Physiol 543:49-70.

Brecht M, Roth A, Sakmann B (2003) Dynamic receptive fields of reconstructed pyramidal cells in layers 3 and 2 of rat somatosensory barrel cortex. J Physiol 553:243-265.

Bruno RM, Sakmann B (2006) Cortex is driven by weak but synchronously active thalamocortical synapses. Science 312:1622-1627.

Buhl EH, Tamás G, Szilágyi T, Stricker C, Paulsen O, Somogyi P (1997) Effect, number and location of synapses made by single pyramidal cells onto aspiny interneurones of cat visual cortex. J Physiol 500:689-713.

Castro-Alamancos MA, Connors BW (1997) Thalamocortical synapses. Prog Neurobiol 51:581-606.

Chattopadhyaya B, Di Cristo G, Higashiyama H, Knott GW, Kuhlman SJ, Welker E, Huang ZJ (2004) Experience and activity-dependent maturation of perisomatic GABAergic innervation in primary visual cortex during a postnatal critical period. J Neurosci 24:9598-9611.

Chmielowska J, Carvell GE, Simons DJ (1989) Spatial organization of thalamocortical and corticothalamic projection systems in the rat SmI barrel cortex. J Comp Neurol 285:325-338.

Dantzker JL, Callaway EM (2000) Laminar sources of synaptic input to cortical inhibitory interneurons and pyramidal neurons. Nat Neurosci 3:701-707.

de Kock CPJ, Bruno RM, Spors H, Sakmann B (2007) Layer- and cell-type-specific suprathreshold stimulus representation in rat primary somatosensory cortex. J Physiol 581:139-154.

Di Cristo G, Wu C, Chattopadhyaya B, Ango F, Knott G, Welker E, Svoboda K, Huang ZJ (2004) Subcellular domain-restricted GABAergic innervation in primary visual cortex in the absence of sensory and thalamic inputs. Nat Neurosci 7:1184-1186.

Dodt HU, Zieglgänsberger W (1990) Visualizing unstained neurons in living brain slices by infrared DIC-videomicroscopy. Brain Res 537:333-336.

Douglas RJ, Martin KAC (2007) Mapping the matrix: the ways of neocortex. Neuron 56:226-238.

Egger V, Nevian T, Bruno RM (2008) Subcolumnar dendritic and axonal organization of spiny stellate and star pyramid neurons within a barrel in rat somatosensory cortex. Cereb Cortex 18:876-889.

Fairén A, DeFelipe J, Regidor J (1984) Nonpyramidal neurons. In: Cerebral domain

All $(n=28)$

ocal inhibitors $(n=12)$

ateral inhibitors $(n=10)$

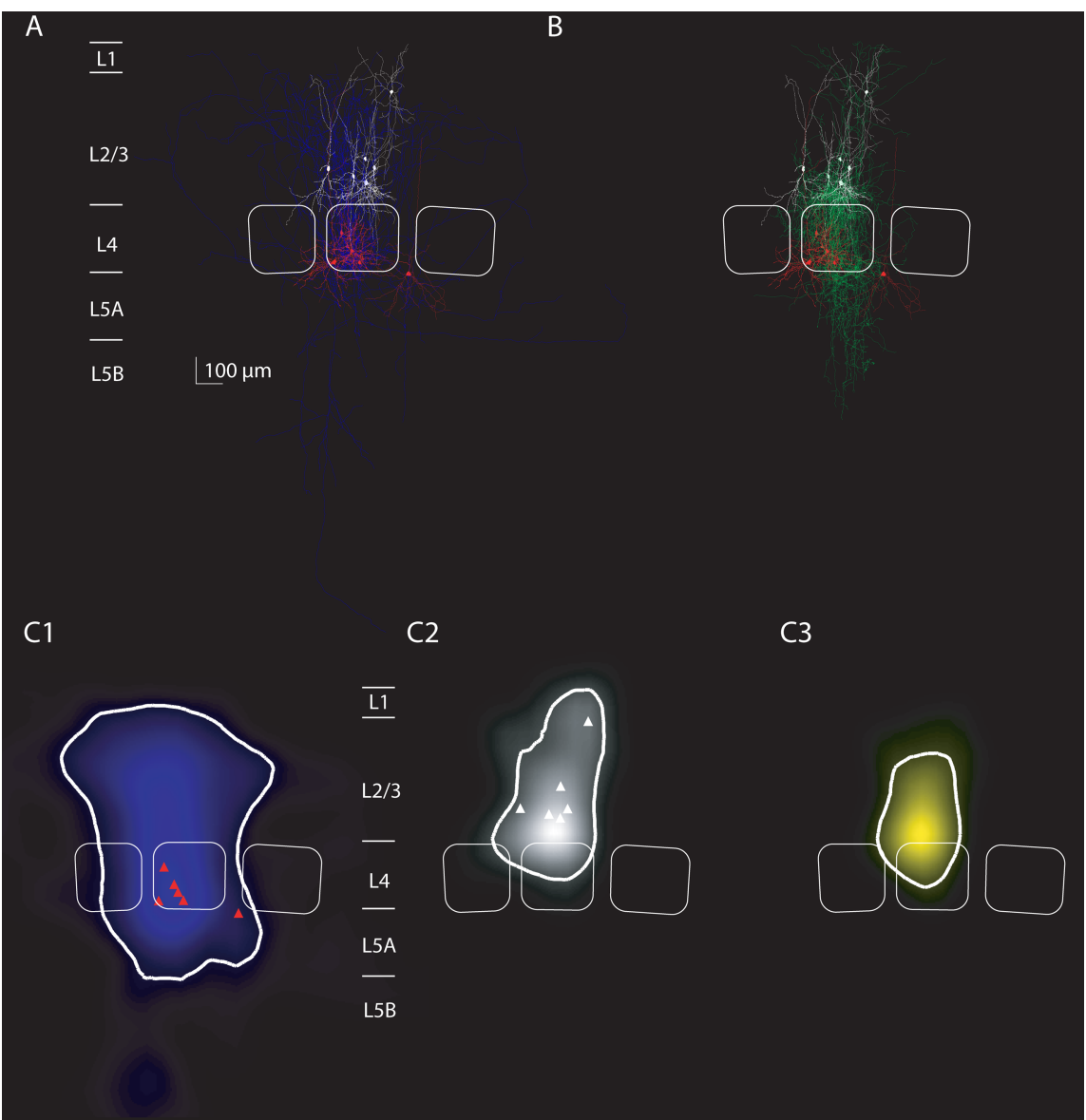

Figure 11. Average projections and innervation domains of $L 4$ spiny neurons projecting to $L 2 / 3$ interneurons of the translaminar inhibitor type. $A$, Overlay of all reconstructions of $L 4$ spiny neurons that were synaptically connected to $L 2 / 3$ interneurons with vertical axonal projection of the postsynaptic interneurons ( $n=6$ with sufficient staining of the axon of $L 4$ spiny neurons). $\boldsymbol{B}$, Overlay of reconstructions of L2/3 interneurons with vertical axonal projections (color code as in Fig. 9). C1-C3, Axonal density maps, dendritic density maps, and innervation domain of L4-to-L2/3 translaminar inhibitor connections. Note that also the

Table 2. Length of presynaptic axons and postsynaptic dendrites in the L4-to-L2/3 interneuron innervation

\section{Type of postsynaptic L2/3 interneuron}

Length of L4 axon in innervation domain

Length of $\mathrm{L} 2 / 3$ dendrite

$(\mu \mathrm{m})$

in innervation domain

5582

$(\mu \mathrm{m})$

1759

5603

5901

5008

1741

1895

1569 axonal path length and the $\mathrm{L} 2 / 3$ interneuron dendritic path length was measured in the innervation domain and averaged for all connections. Values are also reported for L4-to-L2/3 interneuron connections sorted by the axonal projection type of the postsynaptic L2/3 interneuron.

cortex: cellular components of the cerebral cortex (Peters A, Jones EG, eds), pp 206-211. New York: Plenum.

Feldmeyer D, Egger V, Lübke J, Sakmann B (1999) Reliable synaptic connections between pairs of excitatory layer 4 neurones within a single "barrel” of developing rat somatosensory cortex. J Physiol 521:169-190.

Feldmeyer D, Lübke J, Silver RA, Sakmann B (2002) Synaptic connections between layer 4 spiny neurone-layer $2 / 3$ pyramidal cell pairs in juvenile rat barrel cortex: physiology and anatomy of interlaminar signalling within a cortical column. J Physiol 538:803-822.

Feldmeyer D, Roth A, Sakmann B (2005) Monosynaptic connections between pairs of spiny stellate cells in layer 4 and pyramidal cells in layer $5 \mathrm{~A}$ indicate that lemniscal and paralemniscal afferent pathways converge in the infragranular somatosensory cortex. J Neurosci 25:3423-3431.

Gabernet L, Jadhav SP, Feldman DE, Carandini M, Scanziani M (2005) So- 


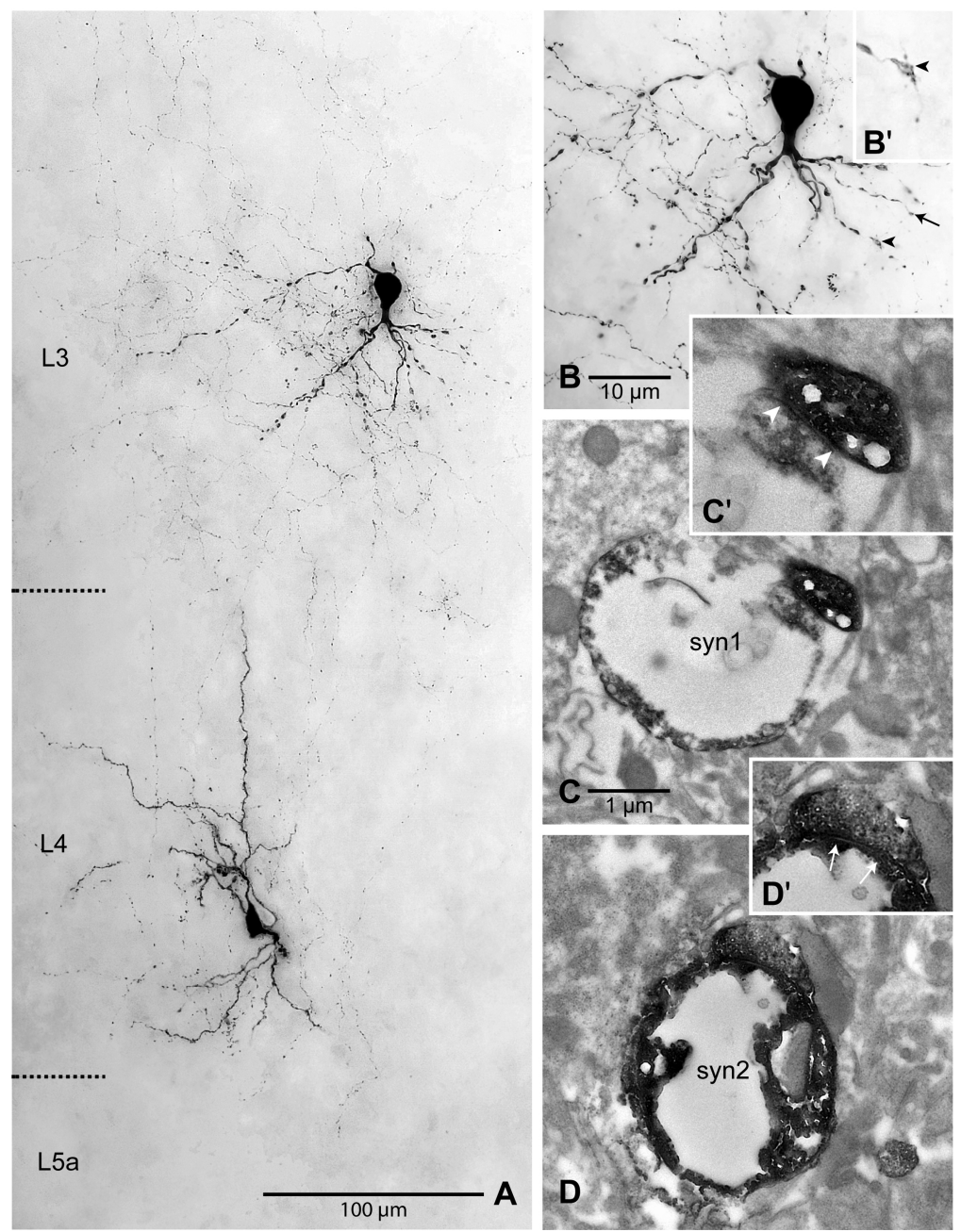

Figure 12. Correlated light- and electron-microscopic analysis of a synaptically coupled $L 4$ spiny stellate neuron-layer $2 / 3$ interneuron pair. $A$, Light-microscopic maximum intensity projection showing the somata, dendrites, and a part of the axons of two biocytin-filled neurons. The maximum intensity projection covered $\sim 60 \mu \mathrm{m}$ in thickness of the slice. Note the numerous ascending axonal collaterals of the spiny stellate neuron. Cortical layers are indicated on the left. $\boldsymbol{B}$, Light-microscopic maximum intensity projection of the $L 2 / 3$ interneuron at higher magnification showing the varicose dendritic tree, most of which is oriented toward the white matter. Two separate very thin axonal branches originating from the spiny stellate neuron contact a secondary (arrow) and a tertiary (arrowhead) dendrite, forming putative synapses. C, Electron-microscopic verification of an asymmetric synapse ("syn1") formed by an axonal bouton with the varicose dendritic segment of the tertiary dendrite. In $C^{\prime}$, the synaptic cleft (arrowheads) can be seen more clearly at higher magnification. $\boldsymbol{D}$, Also the second light microscopically observed contact was

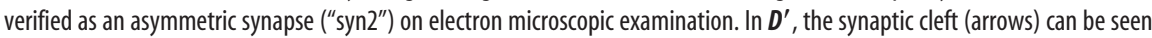
more clearly at higher magnification. Scale bars: $\boldsymbol{A}, 100 \mu \mathrm{m} ; \boldsymbol{B}, 25 \mu \mathrm{m} ; \boldsymbol{C}, \boldsymbol{D}, 1 \mu \mathrm{m}$.

matosensory integration controlled by dynamic thalamocortical feedforward inhibition. Neuron 48:315-327.

Gibson JR, Beierlein M, Connors BW (1999) Two networks of electrically coupled inhibitory neurons in neocortex. Nature 402:75-79.

Grinvald A, Manker A, Segal M (1982) Visualization of the spread of electrical activity in rat hippocampal slices by voltage-sensitive optical probes. J Physiol 333:269-291.

Gupta A, Wang Y, Markram H (2000) Organizing principles for a diversity of GABAergic interneurons and synapses in the neocortex. Science 287:273-278.

Helmstaedter M, Sakmann B, Feldmeyer D (2008a) Neuronal correlates of lateral, local and translaminar inhibition with reference to cortical columns. Cereb Cortex, in press.

Helmstaedter M, Sakmann B, Feldmeyer D (2008b) The relation between dendritic geometry, electrical excitability, and axonal projections of L2/3 interneurons in rat barrel cortex. Cereb Cortex, in press.

Helmstaedter M, Sakmann B, Feldmeyer D (2008c) L2/3 interneuron groups defined by multi-parameter analysis of axonal projection, dendritic geometry and electrical excitability. Cereb Cortex, in press.
Hubel DH, Wiesel TN (1962) Receptive fields, binocular interaction and functional architecture in the cat's visual cortex. J Physiol 160:106-154.

Hubel DH, Wiesel TN (1969) Anatomical demonstration of columns in the monkey striate cortex. Nature 221:747-750.

Jones EG (1984) Neurogliaform or spiderweb cells. In: Cerebral cortex: cellular components of the cerebral cortex (Peters A, Jones EG, eds), pp 409-418. New York: Plenum.

Kapfer C, Glickfeld LL, Atallah BV, Scanziani M (2007) Supralinear increase of recurrent inhibition during sparse activity in the somatosensory cortex. Nat Neurosci 10:743-753.

Kawaguchi Y, Kubota Y (1997) GABAergic cell subtypes and their synaptic connections in rat frontal cortex. Cereb Cortex 7:476-486.

Killackey HP (1973) Anatomical evidence for cortical subdivisions based on vertically discrete thalamic projections from the ventral posterior nucleus to cortical barrels in the rat. Brain Res 51:326-331.

Kim HG, Beierlein M, Connors BW (1995) Inhibitory control of excitable dendrites in neocortex. J Neurophysiol 74:1810-1814.

Koester HJ, Johnston D (2005) Target celldependent normalization of transmitter release at neocortical synapses. Science 308:863-866.

Lu SM, Lin RC (1993) Thalamic afferents of the rat barrel cortex: a light- and electronmicroscopic study using Phaseolus vulgaris leucoagglutinin as an anterograde tracer. Somatosens Mot Res 10:1-16.

Lübke J, Feldmeyer D (2007) Excitatory signal flow and connectivity in a cortical column: focus on barrel cortex. Brain Struct Funct 212:3-17.

Lübke J, Egger V, Sakmann B, Feldmeyer D (2000) Columnar organization of dendrites and axons of single and synaptically coupled excitatory spiny neurons in layer 4 of the rat barrel cortex. J Neurosci 20:5300-5311.

Lübke J, Roth A, Feldmeyer D, Sakmann B (2003) Morphometric analysis of the columnar innervation domain of neurons connecting layer 4 and layer $2 / 3$ of juvenile rat barrel cortex. Cereb Cortex 13:1051-1063.

Marín-Padilla M (1969) Origin of the pericellular baskets of the pyramidal cells of the human motor cortex: a Golgi study. Brain Res 14:633-646.

Markram H, Lubke J, Frotscher M, Roth A, Sakmann B (1997) Physiology and anatomy of synaptic connections between thick tufted pyramidal neurones in the developing rat neocortex. J Physiol 500:409-440.

Markram H, Wang Y, Tsodyks M (1998) Differential signaling via the same axon of neocortical pyramidal neurons. Proc Natl Acad Sci U SA 95:5323-5328.

Meeks JP, Jiang X, Mennerick S (2005) Action potential fidelity during normal and epileptiform activity in paired soma-axon recordings from rat hippocampus. J Physiol 566:425-441.

Mountcastle VB (1957) Modality and topographic properties of single neurons of cat's somatic sensory cortex. J Neurophysiol 20:408-434.

Porter JT, Johnson CK, Agmon A (2001) Diverse types of interneurons generate thalamus-evoked feedforward inhibition in the mouse barrel cortex. J Neurosci 21:2699-2710.

Ramón y Cajal S (1904) Textura del sistema nervioso del hombre y de los vertebrados. Madrid: Imprenta de Nicolás Moya.

Reyes A, Lujan R, Rozov A, Burnashev N, Somogyi P, Sakmann B (1998) Target-cell-specific facilitation and depression in neocortical circuits. Nat Neurosci 1:279-285. 
Sarid L, Bruno R, Sakmann B, Segev I, Feldmeyer D (2007) Modeling a layer 4-to-layer 2/3 module of a single column in rat neocortex: interweaving in vitro and in vivo experimental observations. Proc Natl Acad Sci USA 104:16353-16358.

Schubert D, Kötter R, Luhmann HJ, Staiger JF (2006) Morphology, electrophysiology and functional input connectivity of pyramidal neurons characterizes a genuine layer va in the primary somatosensory cortex. Cereb Cortex 16:223-236.

Schubert D, Kötter R, Staiger JF (2007) Mapping functional connectivity in barrel-related columns reveals layer- and cell type-specific microcircuits. Brain Struct Funct 212:107-119.

Shepherd GM, Svoboda K (2005) Laminar and columnar organization of ascending excitatory projections to layer $2 / 3$ pyramidal neurons in rat barrel cortex. J Neurosci 25:5670-5679.

Simons DJ (1978) Response properties of vibrissa units in rat SI somatosensory neocortex. J Neurophysiol 41:798-820.

Soleng AF, Raastad M, Andersen P (2003) Conduction latency along CA3 hippocampal axons from rat. Hippocampus 13:953-961.

Somogyi P, Nunzi MG, Gorio A, Smith AD (1983) A new type of specific interneuron in the monkey hippocampus forming synapses exclusively with the axon initial segments of pyramidal cells. Brain Res 259:137-142.

Staiger JF, Zilles K, Freund TF (1996) Distribution of GABAergic elements postsynaptic to ventroposteromedial thalamic projections in layer IV of rat barrel cortex. Eur J Neurosci 8:2273-2285.

Staiger JF, Schubert D, Zuschratter W, Kötter R, Luhmann HJ, Zilles K (2002) Innervation of interneurons immunoreactive for VIP by intrinsically bursting pyramidal cells and fast-spiking interneurons in infragranular layers of juvenile rat neocortex. Eur J Neurosci 16:11-20.

Staiger JF, Flagmeyer I, Schubert D, Zilles K, Kötter R, Luhmann HJ (2004) Functional diversity of layer IV spiny neurons in rat somatosensory cortex: quantitative morphology of electrophysiologically characterized and biocytin labeled cells. Cereb Cortex 14:690-701.

Stuart GJ, Dodt HU, Sakmann B (1993) Patch-clamp recordings from the soma and dendrites of neurons in brain slices using infrared video microscopy. Pflugers Arch 423:511-518.

Swadlow HA (2002) Thalamocortical control of feed-forward inhibition in awake somatosensory "barrel" cortex. Philos Trans R Soc Lond B Biol Sci 357:1717-1727.

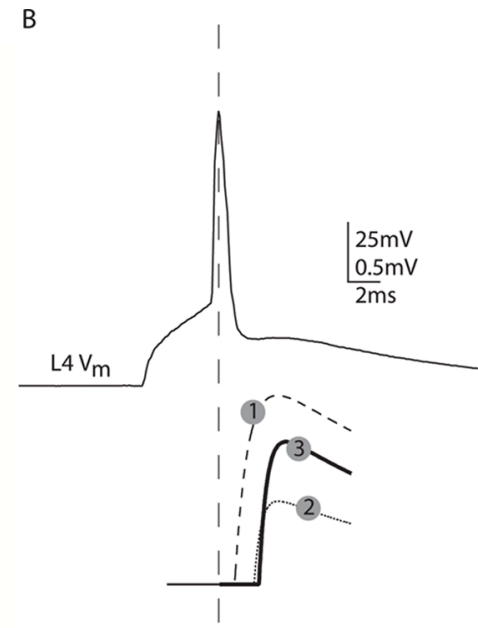

Figure 13. Schematic drawing of the circuitry within and between layers 4 and $2 / 3$. $\boldsymbol{A}$, Thalamic inputs activate $L 4$ spiny in from $L 4$ to $\mathrm{L} / 3$ : excitatory connections from $L 4$ to $\mathrm{L} / 3$ pyramidal neurons are paralleled by excitatory (top evokes EPSPs in three types of neurons (bottom traces are average drawings with average latencies, amplitudes, rise and (2) L2/3 pyramidal cells at 2 ms latency and smaller mplitude, and (3) L2/3 interneurons at 2 ms latency and higher amplitude.

Tamás G, Buhl EH, Somogyi P (1997) Massive autaptic self-innervation of GABAergic neurons in cat visual cortex. J Neurosci 17:6352-6364.

Tamás G, Lorincz A, Simon A, Szabadics J (2003) Identified sources and targets of slow inhibition in the neocortex. Science 299:1902-1905.

Wang Y, Gupta A, Toledo-Rodriguez M, Wu CZ, Markram H (2002) Anatomical, physiological, molecular and circuit properties of nest basket cells in the developing somatosensory cortex. Cereb Cortex $12: 395-410$

Wang Y, Toledo-Rodriguez M, Gupta A, Wu C, Silberberg G, Luo J, Markram H (2004) Anatomical, physiological and molecular properties of Martinotti cells in the somatosensory cortex of the juvenile rat. J Physiol 561:65-90.

White EL, Rock MP (1981) A comparison of thalamocortical and other synaptic inputs to dendrites of two non-spiny neurons in a single barrel of mouse SmI cortex. J Comp Neurol 195:265-277. 